\title{
Stanje ekološkog maslinarstva u Europskoj uniji i Republici Hrvatskoj
}

\section{Sažetak}

Razvoj ekološkog maslinarstva direktno je povezan sa razvojem ekološke poljoprivrede. Prve zabilježene podatke u EUROSTAT-u o količinama ekološki proizvedenih maslina imamo već 2002. godine za Italiju, da bi se od 2009. godine pratila i Hrvatska. Najveći dio ekološke proizvodnje maslina koncentriran je u Španjolskoj, Italiji i Grčkoj. Zakonodavstvo Europske unije (EU) konstantno se zalaže za stimulaciju i rast proizvodnje ekološke hrane i ekološkog načina proizvodnje. U Hrvatskoj, iako proizvodnja ekoloških maslina ima zabilježen značajan porast prinosa kao i uzgojnih površina, nailazimo na nerazumijevanje i nepoznavanje principa ekološke proizvodnje, neučinkovitu zakonsku regulativu, nepostojanje ekoloških rasadnika kao i vrlo mali broj uljara za preradu ekološki proizvedenih maslina.

Ključne riječi: EU, Hrvatska, organska proizvodnja, maslinarstvo

\section{Uvod}

U Europi je u 2016. godini bilo 13,5 milijuna hektara obrađivanih po ekološkim načelima, od čega u Europskoj uniji 12,1 milijuna hektara. Sa više od 2 milijuna hektara, Španjolska je i dalje zemlja s najvećim ekološkim poljoprivrednim površinama u Europi, slijede je Italija (1,8 milijuna hektara) i Francuska (1,5 milijuna hektara). U desetljeću od 2007. godine do 2016. godine ekološko poljoprivredno zemljište EU povećalo se za dvije trećine.

Primjena ekološke poljoprivrede dovodi do manjeg ispiranja hranjivih tvari, veće pohrane ugljika, niže stope erozije kao i niže razine pesticida u vodama (Reganold i sur., 1987; Kreuger i sur., 1999; Mäder i sur., 2002). U posljednjih 20 godina naglo je porasla potražnja za ekološki proizvedenom hranom. Glavni razlozi za povećanje potražnje potrošača za ekološkim Proizvođačma, uključujući maslinovo ulje i stolne masline, odnosi se na: (a) zabrinutost zbog negativnih utjecaja agrokemikalija na okoliš i zdravlje ljudi (npr. mineralna gnojiva, sintetski kemijski pesticidi i regulatori rasta koji se koriste u konvencionalnoj proizvodnji, (b) percepciju potrošača o višoj nutritivnoj vrijednosti ekološki proizvedene hrane i (c) etičkim pitanjima potrošača (Anonymous, 1997, 2002; Benbrook, 2002; Yiridoe i sur., 2005; Oughton i Ritson, 2007; Vassiliou i sur., 2008). Temeljem izvrsnog statusa koji je ostvarila očuvanjem okoliša te činjenice da posjeduje velik udio neobrađenih površina, što podrazumijeva da nije toliko zagađena kemijskim resursima, Hrvatska predstavlja izuzetan potencijal za razvoj ekološke poljoprivrede (Pejnović i Valjak, 2012).

\section{Ekološka proizvodnja maslina u EU i Hrvatskoj}

Ekološka proizvodnja maslina uglavnom se oslanja na: (a) mehaničku kontrolu korova koja na nekim gospodarstvima može biti dopunjena s ispašom životinja; (b) masovno hvatanje i korištenje Bt proizvoda (Bacillus thuringiensis) za suzbijanje maslinove mušice i maslinovog moljca i (c) korištenje organskih gnojiva (od ekološki uzgojene stoke i/ili usjeva koje čine ma-

doc. dr. sc. Kristina Batelja Lodeta, prof. dr. sc. Snježana Bolarić, doc. dr. sc. AlešVokurka, prof.dr.sc. Snježana Kereša, prof.dr.sc. Đani Benčić, doc.dr.sc. Vesna Očić, Sveučilište u Zagrebu Agronomski fakultet, Svetošimunska cesta 25, 10000 Zagreb, Hrvatska Autor za korespondenciju: kbatelja@agr.hr 
hunarke) za poboljšanje plodnosti tla. Nasuprot tome, u intenzivnim konvencionalnim maslinicima koriste se: (a) herbicidi (npr. glifosat) za suzbijanje korova; (b) kemijski pesticidi (npr. organofosforni pesticidi) za kontrolu štetočina; i (c) mineralni NPK Proizvođač kao glavna korištena gnojiva (Kabourakis, 1996, 1999; Volakakis, 2009. godine).

Maslinik pod ekološkom proizvodnjom nadilazi tradicionalni sustav uzgoja u ekonomskom, tehničkom, sociokulturnom i ekološkom smislu (Rocamora i sur., 2013), ali kao jedno od glavnih ograničenja pokazuje se njegova niska produktivnost (Tuomisto i sur., 2012; Tuck i sur., 2014) poglavito, jer ova vrsta proizvodnje zahtijeva upotrebu tehnika koje su manje profitabilne i uključuju dodatne troškove (Mohamad i sur., 2014). No, treba imati na umu da se predanost ekološkom uzgoju ne može opravdati samo ekonomskim i financijskim rezultatima nego se dobiti moraju sagledati i kao moralna i društvena vrijednost (Mzoughi, 2011). Dokazano je da maslinici koji su se obrađivali po ekološkom principu, u periodu od 20 godina, imaju veći udio organskog ugljika u tlu (Parras i Lozano, 2014). Osim smanjenja emisije $\mathrm{CO}_{2}$, neke od prednosti su i akumulacija biomase kao i promocija neto sekvestracije ugljika. Općenito sa voćnjacima (maslinicima) dobiva se i dio drvne mase koja može služiti za hranidbu stoke ili za proizvodnju energije (Infante i González, 2013).

Uzgoj maslina važan je poljoprivredni sektor u Europskoj uniji, osobito u zemljama južne Europe uz obalu Sredozemlja. Više od 95 \% proizvodnje maslina u EU-28 koncentrirano je u državama članicama Španjolskoj, Italiji i Grčkoj. EU je globalni lider u proizvodnji maslina sa gotovo 70 \% ukupne svjetske proizvodnje. Maslinovo ulje je jedan od strateških proizvoda Španjolske s proizvodnim opsegom od oko 60 \% EU i 45 \% svjetske proizvodnje (MAGRAMA, 2016). Španjolska se pozicionirala kao jedan od glavnih proizvođača organskog maslinovog ulja i izvoznika u cijeli svijet (EUROSTAT, 2016), dok je Grčka na trećem mjestu zemalja koja proizvode ekološko maslinovo ulje i masline (EUROSTAT, 2013).

Prema podacima EUROSTAT-a (2019) u periodu od 2002. do 2005. godine jedino Italija ima registrirane podatke o ekološkoj proizvodnji maslina. U tom periodu registrirale su se odvojeno količine organskih maslina za ulje kao i količine za stolne masline (Tablica 1. i 2. i 3.). Od 2009. godine bilježe se podaci za Hrvatsku, a 2010. godine javlja se i Španjolska sa skoro deset puta većom ekološkom proizvodnjom u odnosu na Hrvatsku, dok službenih podataka za Italiju nema sve do 2014. godine (Tablica 4.). U tablici 4. prikazana je ukupna ekološka proizvodnja maslina u periodu od 2012. do 2017. godine gdje vodeće pozicije zauzimaju Italija, Grčka i Španjolska. U Republici Hrvatskoj tijekom 2017. godine evidentirano je 96618 ha pod ekološkom proizvodnjom što čini 6,46 \% u odnosu na ukupne poljoprivredne površine te ukupno 4023 ekoloških proizvođača (DZS, 2018). U 2017. godini ostvaren je šest puta veći prinos u ekološkoj proizvodnji u odnosu na 2012. godinu. Ukupne površine maslinika (Tablica 5.) pod ekološkim načinom proizvodnje od 2007 do 2017. godine porasle su sa 83 ha na 1750 ha (DZS, 2018).

Tablica 1.Ukupna ekološka proizvodnja maslina u tonama.

Table 1. The total organic production of olives in tons.

\begin{tabular}{|c|c|c|c|c|c|c|c|}
\hline GEO/GOD & 2002. & 2003. & 2004. & 2005. & 2009. & 2010. & 2011. \\
\hline Španjolska/Spain & & & & & & 113556 & \\
\hline Hrvatska/Croatia & & & & & 90 & 143 & 90 \\
\hline Italija/Italy & 278573 & 282985 & 293905 & 289114 & & & \\
\hline Slovenija/Slovenia & & & & & & & 52 \\
\hline
\end{tabular}

Izvor/Source: EUROSTAT, 2019. 
Tablica 2. Ekološka proizvodnja stolnih maslina u tonama.

Table 2. Organic production of table olives in tons.

\begin{tabular}{lcc}
\hline GEO/GOD & 2005. & 2010. \\
\hline $\begin{array}{l}\text { Španjolska/Spain } \\
\text { Italija/Italy }\end{array}$ & 8558 & 1106 \\
\hline
\end{tabular}

Izvor/Source: EUROSTAT, 2019.

Tablica 3. Ekološka proizvodnja maslina za ulje u tonama.

Table 3. Organic production of olives for olive oils in tons.

\begin{tabular}{lccc}
\hline GEO/GOD & 2005. & 2010. & 2011. \\
\hline Španjolska/Spain & & 112450 & \\
\hline Italija/Italy & 230802 & & 3 \\
\hline Malta/Malta & 0 & 4 & 52 \\
\hline Slovenija/Slovenia & & & \\
\hline
\end{tabular}

Izvor/Source: EUROSTAT, 2019.

Tablica 4. Ukupna ekološka proizvodnja maslina u tonama.

Table 4. The total organic production of olives in tons.

\begin{tabular}{lcccccc}
\hline GEO/GOD & 2012. & 2013. & 2014. & 2015. & 2016. & 2017. \\
\hline Grčka/Greece & & 20758 & 13925 & 44356 & 128274 & 139913 \\
\hline Španjolska/Spain & 144733 & 148871 & 162593 & 201313 & 164177 & 209704 \\
\hline Hrvatska/Croatia & 155 & 167 & 179 & 611 & 796 & 975 \\
\hline Italija/Italy & & & 267894 & 734886 & 728585 & 5507 \\
\hline Cipar/Cyprus & & 991 & 2990 & 5027 & 498 & 1 \\
\hline Malta/Malta & 100 & 210 & 176 & 340 & 418 & 423 \\
\hline Slovenija/Slovenia & & 39662 & 62664 & 93374 & 168188 \\
\hline Turska/Turkey & & & & & 4 \\
\hline
\end{tabular}

Izvor/Source: EUROSTAT, 2019.

Tablica 5. Ukupna površina maslinika pod ekološkom proizvodnjom u Hrvatskoj, 2007.2017. (DZS, 2018).

Table 5. Total olive orchard area under organic production in Croatia, 2007.-2017. (DZS, 2018).

\begin{tabular}{cccccccccccc}
\hline ha & 2007. & 2008. & 2009. & 2010. & 2011. & 2012. & 2013. & 2014. & 2015. & 2016. & 2017. \\
\hline $\begin{array}{c}\text { Maslinici/ } \\
\text { Olive orchards }\end{array}$ & 83 & 100 & 228 & 322 & 600 & 860 & 1330 & 1472 & 1334 & 1536 & 1750
\end{tabular}

Izvor/Source: DZS, 2019. 
Prema podacima Research Institute of Organic Agriculture - FIBL (2017) RH ima, uz Bugarsku i Cipar, najveći trend rasta ekološke proizvodnje u EU (23 \%). Prema načinu korištenja poljoprivrednih površina u ekološkoj poljoprivredi u razdoblju 2010.-2015. godine najveće povećanje bilježe ekološke livade i pašnjaci. U 2015. godini livade i pašnjaci su sudjelovali sa 44,3 \%, čemu je vjerojatni razlog manje zahtjevna implementacija ekološkog sustava gospodarenja na tim kategorijama poljoprivrednog zemljišta. U strukturi ekoloških površina maslinici sudjeluju sa 1,8\% (Gugić i sur., 2017).

Republika Hrvatska ima izuzetan potencijal za razvoj ekološke poljoprivrede radi kvalitetno očuvanih prirodnih resursa i čistih poljoprivrednih površina koji pogoduju proizvodnji ekoloških proizvoda. Ono što mnogi smatraju, a očito je riječ o zabludi, da se zapušten maslinik u kojem se ne provodi zaštita i gnojidba kemijskim sredstvima smatraju ekološkim uzgojem. Ekološka poljoprivreda kao takva i nije samo način poljoprivredne proizvodnje, gdje bi se trebala poštivati donesena pravila, ona doprinosi očuvanju okoliša i biodiverziteta, uzima u obzir ekološku inteligenciju gdje se ponovno pokušava ostvariti povezanost i razumijevanje čovjeka i prirode. Nepoštivajući čovjekovu sposobnost prilagođavanja svom ekološkom okruženju, odnosno ekološku inteligenciju koja se odnosi na razumijevanje živih organizama i njihovog ekosustava te obuhvaća učenje iz iskustva na temelju kojeg će se čovjek efikasno odnositi prema svojoj okolini (Goleman, 2010), proizvođač nikad neće ustrajati na proizvodnji po ekološkim načelima niti će ju u potpunosti moći razumjeti. U Hrvatskoj ekološko maslinarstvo u stvarnosti nije u potpunosti zaživjelo radi nepostojanja ekoloških rasadnika gdje bi se mogle nabaviti ekološki dobivene sadnice određenih sorti masline, vrlo malog broja ekoloških uljara koje bi mogle iz ekoloških maslina Proizvođačti ekološko ekstra djevičansko maslinovo ulje, radi neučinkovite Zakonske regulative, kao i nedovoljno percepcije o značenju ekološke svijesti.

\section{Zakonska regulativa}

Uredbom (EZ) br. 834/2007 (EZ 2007) Europsko Vijeće ministara poljoprivrede donijelo je zakonsku regulativu o proizvodnji i označavanju ekoloških proizvoda. Ta je politika definirala ciljeve, načela i opća pravila za ekološku proizvodnju i zamijenila Uredbu (EEZ) 2092/91.

Rezultat navedenog bilo je povećanje površina sa ekološkim uzgojem, koje su u periodu od 2000. do 2012. godine rasle za 6,7 \% na godišnjoj razini (9,6 milijuna ha) odnosno 5,4 \% od ukupne poljoprivredne površine EU (COM, 2014). U razdoblju od 2012 do 2013. godine Europska komisija revidirala je dokument Europske politike o ekološkoj poljoprivredi donijevši Akcijski plan o budućnosti ekološke proizvodnje u Europi (COM, 2014). Također, Plan ruralnog razvoja za period od 2014. do 2020. godine predviđa posebnu mjeru za prepoznavanje važnosti ekološkog uzgoja kao jedan od uzroka razvoja ruralnih područja.

Broj gospodarstava koja su se bavila ekološkom proizvodnjom 1991. godine iznosio je manje od 20.000 (Ekološka poljoprivreda u Europi) da bi u 2014. godini taj broj iznosio 340.000 proizvođača (EC, 2013). Taj porast najviše se odrazio u Španjolskoj, Francuskoj, Njemačkoj i Poljskoj. Prema EUROSTAT-u (2015) u Austriji je zabilježen najveći udio ekološke proizvodnje u odnosu na ukupnu poljoprivrednu površinu od 20,3 \%, zatim slijedi Švedska sa 17,1 \% te Estonija sa $15,7 \%$.

Između 2010. i 2017. godine došlo je do značajnog povećanja poljoprivrednog zemljišta namijenjenog organskom uzgoju. U 2017. godini udio poljoprivrednog zemljišta EU namijenjenog organskoj proizvodnji u ukupnom zemljištu je $7 \%$, što predstavlja porast od $70 \%$ u odnosu na 2009. godinu. To odražava veličinu tržišta EU-a od gotovo 34,3 milijarde eura u maloprodaji ekoloških proizvoda u 2017. godini. Rastuća domaća potrošnja dopunjena je snažnim uvoznim sektorom. Ova rastuća potražnja za ekološkim Proizvođačma također se dobro odražava u godišnjim izdacima po stanovniku, koji su u prosjeku iznosili 67 eura u 2017. godini, 
u usporedbi s 29 eura u 2007. godini (EC, 2019).

Prema novoj strategiji-CAP (2014. -2020.) predviđene su potpore za ekološke proizvođače u vidu - Pillar 1 (izravna plaćanja) i Pillar 2 (Ruralni razvojni programi - RDPs), odnosno, certificirani ekološki proizvođači kvalificirani su za primanje tzv. 'zelenog plaćanja'. Primjena ovih novih mjera započela je 2015. godine u velikom broju zemalja članica EU koji su započeli sa plaćanjem konverzije zemljišta u ekološko kao i održavanja ekološke poljoprivrede (FIBL i IFOAM, 2016), pa tako plaćanja za udio u ekološkoj poljoprivredi predstavljat će ukupno oko 6,4 \% javnih rashoda predviđenih za Program ruralnog razvoja do 2020. godine (FIBL i IFOAM, 2016). Zemlje članice EU tijekom 2017. godine imale su priliku premjestiti $15 \%$ proračuna sa potpore Pillar 1 u potporu Pillar 2 za 2018. i 2019. godinu, što ukazuje na još veće zalaganje za stimulaciju i rast proizvodnje ekološke hrane i ekološkog načina proizvodnje.

U Republici Hrvatskoj sve Uredbe i Pravilnici usklađeni su sa zakonodavstvom EU. Program ruralnog razvoja Republike Hrvatske za razdoblje 2014. - 2020. determinira sedamnaest mjera i šest prioriteta koje je propisala Europska komisija. Pomoću ovog programa Hrvatska dobiva značajne potpore Europskog privrednog fonda za ruralni razvoj dok u sufinanciranju sudjeluje i Državni proračun Republike Hrvatske (Znaor i Karoglan Todorović, 2016)

Ekološki uzgoj (M11) jedna je od najvažnijih mjera Programa ruralnog razvoja 2014. - 2020. provedbom ove mjere važno je usmjeriti nove poljoprivrednike u koncept ekološke proizvodnje te motivirati eko - poljoprivrednike da nastave sa svojom praksom.

\section{Zaključak}

Na području Europske unije od početka 2000. godine bilježi se porast ekološke proizvodnje maslina. Gotovo 70 \% ukupne svjetske, te više od 95 \% europske ekološke proizvodnje maslina koncentrirano je u Španjolskoj, Italiji i Grčkoj. U Hrvatskoj, iako je proizvodnja ekoloških maslina registrirana i u EUROSTAT-u od 2009. godine te ima zabilježen značajan rast u periodu od 2012. do 2017. godine, u stvarnosti nailazimo na brojne prepreke poput nerazumijevanja i potpunog nepoznavanja principa ekološke proizvodnje, obaveznog trogodišnjeg razdoblja za prijelaz na ekološku poljoprivredu radi nepostojanja ekoloških rasadnika kao i vrlo malog broja ekoloških uljara.

\section{Literatura}

Anonymous (1997) Organic and ethical foods: market intelligence. Mintel International Group Ltd., Rockville, MD.

Anonymous (2002) Organic farming, food quality and human health: a review of the evidence. The Soil Association, Bristol, UK.

Benbrook, C.M. (2002) Organochlorine residues pose surprisingly high dietary risks. Journal of Epidemiology and Community Health 56, 822-823.

COM (2014) Communication from the commission to the European Parliament, the council, the European economic and social committee and the committee of the regions. 179 final. Action Plan for the future of Organic Production in the European Union.

Biljna proizvodnja u 2017. (2018). Državni zavod za statistiku RH.

European Commission (EC) (2013) Facts and figures on organic agriculture in the European Union. Agriculture and Rural Development. https://ec.europa.eu/agriculture/sites/agriculture/files/markets-and-prices/more-reports/pdf/organic-2013_en.pdf.

Eurostat Database. Available online: http://ec.europa.eu/eurostat/data/database

Eurostat (2013) Agriculture, forestry and fishery statistics, European Commission, 2013 edition, pp 80-81, Luxembourg: Publications Office of the European Union, 2013. http://epp.eurostat.ec.europa.eu/cache/ITY_OFFPUB/KSFK-13-001/EN/KS-FK-13-001-EN.PDF

European Commission (EC) (2019) Organic farming in the EU: a fast growing sector, EU Agricultural Markets Briefs. FIBL and IFOAM (2016) The world of organic agriculture. Statistics and emerging trends 2016. https://shop.fibl.org/ fileadmin/documents/shop/1698-organic-world-2016.pdf.

FIBL and IFOAM (2017) The world of organic agriculture. Statistics and emerging trends 2017. https://shop.fibl.org/ $\mathrm{CHen/mwdownloads/download/link/id/785/?ref=1}$

Goleman, D. (2010) Ekološka inteligencija (Poznavanje skrivenih utjecaja onoga što kupujemo). Beograd, Geopoetika.

Gugić J., Grgić I., Dorbić B., Šuste M., Džepina M., Magdalena Zrakić (2017) Pregled stanja i perspektiva razvoja 
ekološke poljoprivrede u Republici Hrvatskoj, Glasnik zaštite bilja 3, 20-30.

Infante, A.J.; González, M.M. (2013) The socio-ecological transition on a crop scale: the case of olive orchards in southern Spain (1750-2000). Hum Ecol 41, 961-969. https://doi.org/10.1007/s10745-013-9618-4.

Kabourakis, E. (1996) Prototyping and dissemination of ecological olive production systems: a methodology for designing and dissemination of prototype ecological olive production systems (EOPS) in Crete. Thesis, Landbouw Universiteit, Wageningen.

Kabourakis, E. (2000) Learning processes in designing and disseminating ecological olive production systems in Crete. In: Knowing and learning for change in agriculture: case studies from industrialised countries, ed. M. Cerf, D. Gibbon, B. Hubert, J. Jiggins, M. Paine, J. Proost, \& N. Rolling. INRA Editions, Paris, 97-111.

MAGRAMA (Ministerio de Agricultura, Alimentación y Medio Ambiente). Informe Anual de la Industria Alimentaria Española. Periodo 2014-2015, (2016) Subdirección General de Calidad Diferenciada y Agricultura Ecológica, Gobierno de España: Madrid, Spain.

Oughton, E., \& Ritson, C. (2007) Food consumers and organic agriculture. Handbook of Organic Food Qualitya nd Safety. CRC Press, Boca Raton, FL, 74-94.

Parras, A.L.; Lozano, G.B. (2014) Conventional tillage vs. organic farming in relation to soil organic carbon stock in olive groves inMediterranean rangelands (southern Spain). Solid Earth Discuss 6:35-70. https://doi.org/10.5194/ sed-6-35-2014

Pejnović, A.; Valjak,V. (2012) Ekološka poljoprivreda Hrvatske: Problemi i mogućnosti razvoja, Hrvatski geografski glasnik, 74 (1), 141.-159.

Rocamora, B.; Colombo, S.; Sayadi, S.; Estévez, C. (2013) Los impactos marginales del olivar ecológico de montaña andaluz frente al convencional post-condicionalidad: Una visión de los expertos. Rev. Esp. Estud. Agrosoc. Pesq., 234, 49-82.

Vassiliou, A., Kabourakis, E., Papadopoulos, D. (2008) Traceability and ethical traceability in the Greek olive oil chain. In: Ethical traceability and informed choice, ed. C. Coff, D. Barling, M. Korthals, \& T. Nielsen. Springer, Berlin, 167-191

Volakakis, N. (2009) Alternative strategies for the control of fruit flies in organic olive production. PhD thesis, Newcastle University, UK.

Yiridoe, E. K., Bonti-Ankomah, S. \& Martin, R.C. (2005) Comparison of consumer perceptions and preference toward organic versus conventionally produced foods: a review and update of the literature. Renewable Agriculture and Food Systems 20, 193-205.

Znaor, Darko and Karoglan Todorović, Sonja (2016) Poljoprivreda koja štiti prirodu: zaštira pridode kroz mjere Programa ruralnog razvoja RH 2014.-2020. Ministarstvo zaštite okoliša i prirode Republike Hrvatske i konzorcij u sastavu: Avalon Foundation, Nizozemska, ÖKL, Austrija i Ecologica, Hrvatska, Zagreb.

Prispjelo/Received: 5.6.2019.

Prihvaćeno/Accepted: 3.7.2019.

Review paper

\section{The state of organic olive growing in the European Union and the Republic of Croatia}

\section{Abstract}

The development of organic olive oil production directly is related to the development of organic agriculture. The first recorded data in EUROSTAT on quantities of organically produced olives has been for Italy for year 2002 and for Croatia for year 2009. The largest part of organic olive production is concentrated in Spain, Italy and Greece. European Union (EU) legislation is constantly advocating for the stimulation and growth of organic food production and organic production. In Croatia, although production of organic olive trees has recorded a significant increase in yields as well as growing areas, we encounter misunderstanding and ignorance of the principles of organic production, ineffective legal regulation the absence of organic nurseries as well as a very small number of organic oil refineries for the processing of organically produced olives.

Keywords: EU, Croatia, organic production, olive growing 